\title{
Evaluación clínica de suturas sintéticas en ginecología
}

\section{* SAULO MUÑ̃Z DELG ADO}

Tradicionalmente se han venido utilizando diferentes materiales de suturas sin qu hasta el presente se hubiera descubierto una totalmente satisfactoria, exenta de reacciones secundarias. En esta búsqueda se ha presentado un nuevo material absorvible derivado del ácido poliglicólico (DEXON), el cual hemos ensayado en el campo Ginecológico.

La mayoría de estas suturas han sido experimentadas inicialmente en animales y luego se verifica su aceptabilidad y condiciones en los humanos.

\section{MATERIAL Y METODOS:}

Se tomaron pacientes de consultorio privado (S.M.D.) a quienes se les practicaron histerectomías abdominales y vaginales de acuerdo con las técnicas claśicas. Se establecieron dos grupos, lo cual fue fácil debido a que estas pacientes fueron a dos Instituciones diferentes y sólamente en una contábamos con dicho material de sutura: a) con suturas sintéticas y b) con catgut. Para la sutura del muñón vaginal se empleó cat gut-crómico número 0 ó número 1 y sutura sintética número $0(\mathrm{DEXON})$.

Se afrontó el muñón vaginal con puntos separados y cruzados tanto en las histerectomías abdominales como en las vaginales. En los casos de cat gut se emplearon agujas corrientes similares a las que traen las suturas sintéticas.

Se utilizó material de sutura sintética durante todos los tiempos del acto quirúrgico con excepción de la fascia de los músculos abdominales que se suturó con hilo, y de la piel que la afrontamos con hilo o seda.

\section{* PROFESOR}

AREA MATERNO INFANTIL

FACULTAD DE MEDICINA

UNIVERSIDAD LIBRE DE CALI
Se estudiaron las reacciones secundarias, especialmente en el muñón vaginal con el fin de constatar todo el proceso de cicatrización.

Tuvieron controles entre los 12-15 días del post- operatorio y posteriormente otro por lo menos al mes.

RESULTADOS:

I NUMERO DE CASOS DE HISTERECTOMIAS

\begin{tabular}{|crl|}
\hline DEXON & 85 & Junio 1975 - Julio 1977 \\
CATGUT & 90 & Diferentes años 1973-1977 \\
175 & & \\
\hline
\end{tabular}

II INDICACIONES DE LS INTERVENCIONES Y MATERIAL USADO

\begin{tabular}{|c|c|c|c|}
\hline & DEXON & CATGUT & TOTAL \\
\hline $\begin{array}{l}\text { Fibromioma- } \\
\text { tosis }\end{array}$ & & & \\
\hline $\begin{array}{l}\text { tosis } \\
\text { Prolapso }\end{array}$ & 27 & 24 & 51 \\
\hline endome- & 40 & 50 & \\
\hline triosis & 2 & 3 & 5 \\
\hline $\begin{array}{l}\text { Ca. In Situ } \\
\text { Displasias }\end{array}$ & 2 & 3 & 5 \\
\hline Cervicales & 3 & 6 & 9 \\
\hline Otros & 3 & 4 & 7 \\
\hline TOTAL & 85 & 90 & 175 \\
\hline
\end{tabular}

En el análisis de los casos intervenidos que se suturaron con diferentes materiales se registraron similitudes en cuanto a cicatrización, morbilidad etc. La única diferencia significativa fué la presencia o ausencia de granulomas en la cúpula vaginal.

\section{*DIRECTOR}

PROFAMILIA CALI 


\section{TECNICAS DELA HISTERECTOMIA Y MATERIALES USADOS}

\begin{tabular}{|l|c|c|r|}
\hline VAGINA- & DEXON & CATGUT & TOTAL \\
$\begin{array}{l}\text { LES } \\
\text { ABDOMI- } \\
\text { NALES }\end{array}$ & 62 & 50 & 112 \\
\hline TOTAL & 83 & 40 & 63 \\
\hline
\end{tabular}

Al comparar los dos grupos tratados con diferentes materiales de sutura se observó la presencia de granulomas en el $11.3 \%$ de los casos con sutura sintética comparadas con el $83.5 \%$ de los intervenidos con catgut.

IV GRANULOMAS DE LA CUPULA VAGINAL EN LOS PACIENTES INTERVENIDOS

\begin{tabular}{|l|c|c|c|}
\hline VAGINA- & DEXON. & CATGUT & TOTAL \\
LES & 6 & 42 & 48 \\
ABDOMI- & 5 & 19 & 24 \\
\hline NALES & 11 & 61 & 72 \\
\hline TOTAL & & & \\
\hline
\end{tabular}

\section{RESUMEN}

La utilización de un nuevo material de sutura en cirugia ginecológica impone el estudio cuidadoso de sus ventajas y de sus inconvenientes en su uso, con el objeto de recomendarlo o bien desecharlo. El autor establece una comparación entre casos tratados con sutura tradicional de catgut y otros en los cuales se utilizó sutura sintética No. 0 . El total de casos observados fué de ciento setenta y cinco ( 90 de control y 85 casos por concluir). La única diferencia significativa fué la presencia o ausencia de granulomas en la cúpula vaginal. Encontrándose tal complicación en el $83.5 \%$ de los casos en los cuales se usó el material tradicional, en comparación con un $11.3 \%$ en los casos tratados con el nuevo material.

\section{SUMMARY}

To use a new stitching material in gineacological surgery requires a carefull study on the advantages and disadvantages of its use in order to recommend or reject it. The author compares cases treated with cutgut traditional stitch, with cases where No. 0 synthetic stitch was used. 175 cases were observed ( 90 for control and 85 cases to be concluded). The only important difference was the presence or absence of granuloms in the vaginal shell. Such complication was found in $83.5 \%$ of the cases where traditional material was used, and in $11.3 \%$ of thecases treated with the new material.

\section{BIBLIOGR AFIA}

- Cervantes, M. A. (México). "Suturas Sintéticas Absorbibles en Aparato Génito Urinario, Revista Mexicana de Urología, XXXX: 4 (295 -304) Julio - Agosto 1969.

- Morgan M. N. (Reino Unido). New Synthetic Absorbable Suture Material. British Medical Journal, 2:308, Mayo 3 de 1969.

- Sanguinés F., A., et al. (méxico). Suturas Sintécicas en Ciriguía Vagino perineal, Ginecología y Obstetricia de México, 26: 155 (389397) Sep. 1969.

- Mouzas, G. L. Pompa P. "The use of Dexon and plain catgut in circumcision. Br. J. Surg. Vol. 61 (1974) 313-317.

- Echeverria E., Jiménez J.: Evaluation of an absorbable synthetic suture material. Surg Gynec Obst. 131: 1-14, 1970.

- Wallace WR, Maxwell GR, Cavalaris CJ: Comparison of Polyglycolic acid suture to black silk, chromic and plain catgut in humen oral tissues. J. Oral Surg 28: 739-746, 1970. 